\title{
Mg II spectral line broadening in helium, oxygen and argon-helium plasmas
}

\author{
S. Djeniže $e^{1,2}$, S. Bukvić ${ }^{1,2}$, A. Srećković ${ }^{1,2}$, and M. Platiša ${ }^{1}$ \\ ${ }^{1}$ Faculty of Physics, University of Belgrade, 11001 Belgrade, PO 368, Serbia \\ e-mail: steva@ff.bg.ac.yu \\ ${ }^{2}$ Isaac Newton Institute of Chile, Yugoslavia Branch, Belgrade, Serbia
}

Received 31 January 2004 / Accepted 3 May 2004

\begin{abstract}
Stark widths $(W)$ and shifts $(d)$ of the astrophysically very important six $(279.0777,279.5528,279.7998,280.2705$, 292.8633 and $293.6510 \mathrm{~nm}$ ) singly ionized magnesium (Mg II) spectral lines in helium, oxygen and argon-helium plasmas have been measured at electron temperatures between 30000 and $52300 \mathrm{~K}$ and electron densities between $1.2 \times 10^{23}$ and $1.65 \times$ $10^{23} \mathrm{~m}^{-3}$. They are the first experimental results obtained at electron temperatures higher than $20000 \mathrm{~K}$. A linear, low-pressure, pulsed arc has been used as an optically thin plasma source. The magnesium atoms, as impurities in the driving gases, have been introduced by erosion from the pure magnesium bands fixed on the discharge electrodes. Our measured Stark width and shift values have been compared to the existing experimental and theoretical data. We have found a good agreement with $W$ and $d$ values calculated by the semiclassical perturbation formalism (SCPF).
\end{abstract}

Key words. plasmas - line: profiles - atomic data

\section{Introduction}

The singly ionized magnesium (Mg II) spectral lines (279.0777, 279.5528, 279.7998, 280.2705, 292.8633 and $293.6510 \mathrm{~nm}$ ) in the $1 \mathrm{UV}, 2 \mathrm{UV}$ and $3 \mathrm{UV}$ multiplets are very useful for investigations of various cosmic light sources, especially the resonance $\mathrm{Mg}$ II $h \& k$ lines $(279.5528 \mathrm{~nm}$ and $280.2705 \mathrm{~nm}$ ). They are used in astrophysical plasma diagnostics and modeling (Danezis et al. 2003; Eracleous \& Halpern 2003; Bohm-Vitense et al. 2001; Arav et al. 2001; Lobel \& Dupree 2000; Charlton et al. 2000; Wood \& Karovska 2000; Luttermoser 2000; Popović et al. 2001; Uitenbroek \& Briand 1995 , and in many other studies). Therefore, knowledge of the $\mathrm{Mg}$ II spectral line characteristics (the widths and the shifts) are of interest. In the case when the Stark broadening is the principal pressure-broadening mechanism in plasmas (Griem 1974) various plasma compositions and kinetic processes (Lesage 1995; Zeippen 1995) can be modelled relying on the Stark width and shift values. The mentioned $\mathrm{Mg}$ II line profile characteristics have been investigated in a few experiments (Chapelle \& Sahal-Bréchot 1970; Roberts \& Barnard 1972; Purić \& Konjević 1972; Helbig \& Kusch 1972; Hadžiomerspahić et al. 1973; Kusch \& Schweicker 1976; Fleurier et al. 1977). In all of the mentioned experiments magnesium atoms are introduced through magnesium salts deposited on the discharge electrodes or by working gases which contain magnesium in complex molecular structures.
The aim of our paper is contribution to the knowledge of the Stark FWHM (full-width at a half intensity maximum, $W$ ) and Stark shift $(d)$ of the prominent Mg II lines in different plasma compositions at electron temperatures higher than $20000 \mathrm{~K}$ (Konjević et al. 2002, and references therein). Our plasmas contain magnesium atoms as impurities in the driving gases, which provides conditions free of self-absorption in the $\mathrm{Mg}$ II 2 UV and 3 UV multiplets in our plasma compositions. Our measured $W$ and $d$ values are compared to the existing measured and calculated (Griem 1974; Chapelle \& Sahal-Bréchot 1970; Dimitrijević \& Sahal-Bréchot 1995) data.

\section{Experiment}

A linear low pressure arc has been used as a plasma source. A pulsed discharge was driven in a pyrex discharge tube of $5 \mathrm{~mm}$ inner diameter and plasma length of $14 \mathrm{~cm}$ (Fig. 1 in Djeniže et al. 1991). The tube has end-on quartz windows. The magnesium atoms were introduced through erosion of the magnesium metal bands fixed on the discharge electrodes following the idea described in Djeniže et al. (1990a,b, 1991, 1992). The working gases were helium, oxygen and argonhelium $(72 \% \mathrm{Ar}+28 \% \mathrm{He})$ mixture in flowing regime at a $133 \mathrm{~Pa}$ pressure in the oxygen and argon-helium plasmas and at a $532 \mathrm{~Pa}$ pressure in the helium plasma. Even if the density of magnesium atoms was low, a discharge length of $14 \mathrm{~cm}$ was sufficient to provide a measurable intensity of $\mathrm{Mg}$ II lines. A capacitor of $14 \mu \mathrm{F}$ was charged up to $55 J$ bank energy. 


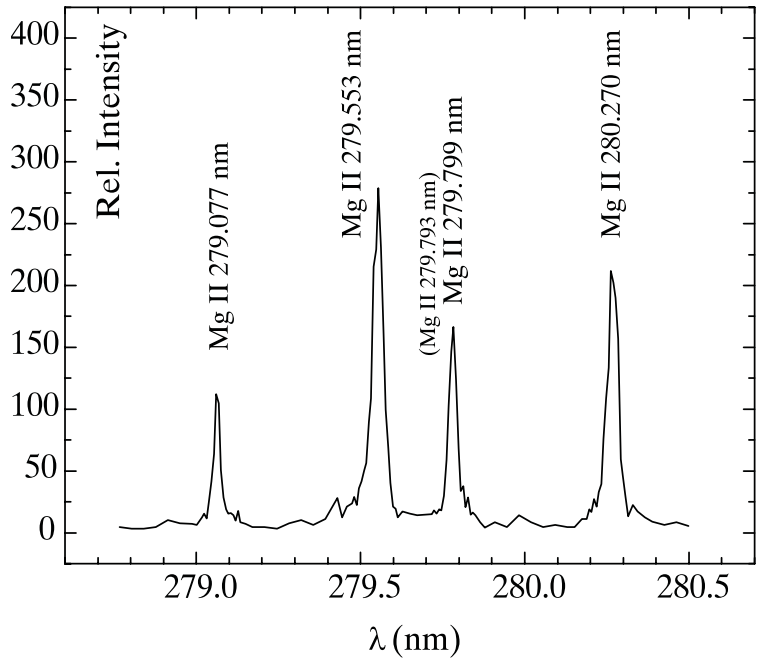

Fig. 1. Recorded Mg II spectral lines in the 1 UV (279.553 nm and $280.270 \mathrm{~nm})$ and $3 \mathrm{UV}(279.077 \mathrm{~nm}$ and $279.799 \mathrm{~nm})$ multiplets in the helium plasma.

Spectroscopic observation of isolated spectral lines was made end - on along the axis of the discharge tube. The line profiles were recorded using a step-by-step technique described in our previous publications (Djeniže et al. 2002, 2003). The averaged photomultiplier signal (seven shots at the same spectral range) was digitized using an oscilloscope interfaced to a computer. The recorded Mg II spectral line profiles are shown in Figs. 1 and in $3 \mathrm{a}$.

The absence of the self-absorption, in the case of the $2 \mathrm{UV}$ and $3 \mathrm{UV}$ multiplets, was proved using the method described by Djeniže \& Bukvić (2001). However, in the case of the resonance $\mathrm{Mg}$ II $h \& k$ lines (in the multiplet $1 \mathrm{UV}$ ) presence of the self-absorption was found. Consequently, the Stark widths of the $279.553 \mathrm{~nm}$ and $280.270 \mathrm{~nm}$ lines are not presented in this work. The plasma parameters were determined using standard diagnostic methods (Griem 1964). The electron temperature $(T)$ was obtained using the relative line intensity ratio method between the He II $P_{\alpha} 468.6 \mathrm{~nm}$ and the He I $587.6 \mathrm{~nm}$ lines in the case of the helium plasma within $\pm 8 \%$ accuracy. In the cases of the oxygen and argon-helium plasmas the Saha equation was applied using O III $(326.08 \mathrm{~nm}$, $372.09 \mathrm{~nm}$ and $375.99 \mathrm{~nm})$, O II $(327.05 \mathrm{~nm}, 372.73 \mathrm{~nm}$ and $374.95 \mathrm{~nm})$, Ar III (330.19 nm, $331.12 \mathrm{~nm}, 334.48 \mathrm{~nm}$, $335.85 \mathrm{~nm}, 336.59 \mathrm{~nm}, 302.39 \mathrm{~nm}$ and $302.71 \mathrm{~nm})$ and Ar II (329.36 nm, $330.72 \mathrm{~nm}, 335.09 \mathrm{~nm}, 302.89 \mathrm{~nm}$ and $347.67 \mathrm{~nm}$ ) lines. These $T$ values are obtained within $6 \%$ uncertainties. The electron density $(N)$ decays were measured using a well-known single wavelength $\mathrm{He}-\mathrm{Ne}$ laser interferometer technique (Ashby et al. 1965) for the $632.8 \mathrm{~nm}$ transition with an estimated error of $\pm 7 \%$. Necessary atomic date were taken from NIST (2004). Temporal evolution of the $N$ and $T$ values are presented in Fig. 2.

\section{Line width and shift measurements}

The measured profiles were of the Voigt type due to the convolutions of the Lorentzian Stark and Gaussian profiles caused by

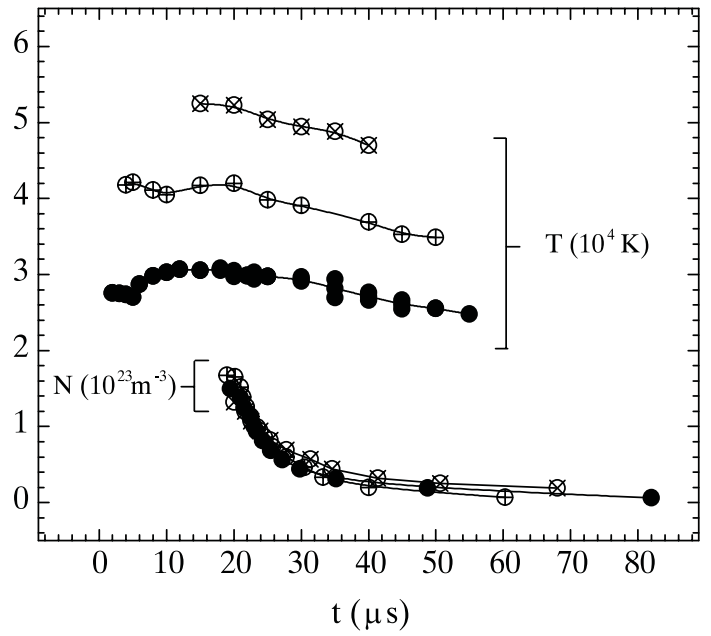

Fig. 2. Electron temperature $(T)$ and electron density $(N)$ decays in helium $(\otimes)$, oxygen $(\oplus)$ and argon-helium $(\bullet)$ plasmas.

Doppler and instrumental broadening. For the electron density and temperature in our experiment the Lorentzian fraction was dominant. Van der Waals (Griem 1974) and resonance (Griem 1974) broadening were estimated to be smaller by more than one order of magnitude in comparison to Stark, Doppler and instrumental broadening. The standard deconvolution procedure (Davies \& Vaughan 1963) was applied using the least squares algorithm. The Stark widths were measured within $\pm 12 \%$ error at a given $N$ and $T$. Our measured Stark FWHM $\left(W_{\mathrm{m}}\right)$ are presented in Table 1. The Stark shifts $(d)$ were measured relative to the unshifted spectral lines emitted by the same plasma (Purić \& Konjević 1972). Stark shift data are corrected for the electron temperature decay.

\section{Results and discussion}

Our measured $W_{\mathrm{m}}$ and $d_{\mathrm{m}}$ values are presented in Table 1 .

In order to compare measured and calculated Stark FWHM and shift values, the theoretical Stark FWHM and shift dependences on the electron temperature together with the values of other authors and our experimental results, at an electron density of $1 \times 10^{23} \mathrm{~m}^{-3}$ are graphically presented in Figs. 3-4.

Our Stark FWHM are in agreement with theoretical values calculated by Dimitrijević \& Sahal-Bréchot (1995) based on the semiclassical perturbation formalism (Sahal-Bréchot 1969a,b) (see Figs. 3b and 4a). One can see that previously published (Griem 1974) Mg II $W$ values are, also, in tolerable agreement with our results within the experimental accuracy of $\pm 12 \%$ and within the uncertainties $( \pm 30 \%)$ of the calculations.

In the case of the Stark shifts the situation is different. Namely, the recently calculated DSB values (Dimitrijević \& Sahal-Bréchot 1995) lie below the previous theoretical G (Griem 1974) data. Our $d_{\mathrm{m}}$ values agree very well with the DSB theoretical predictions, especially in the case of helium and oxygen plasmas. It turns out that inclusion of the helium ion contribution in the total (electron + ion) Stark FWHM and shift give DSB values with excellent agreement with our measured $W_{\mathrm{m}}$ and $d_{\mathrm{m}}$ (see value with asterix in Table 1 and the 

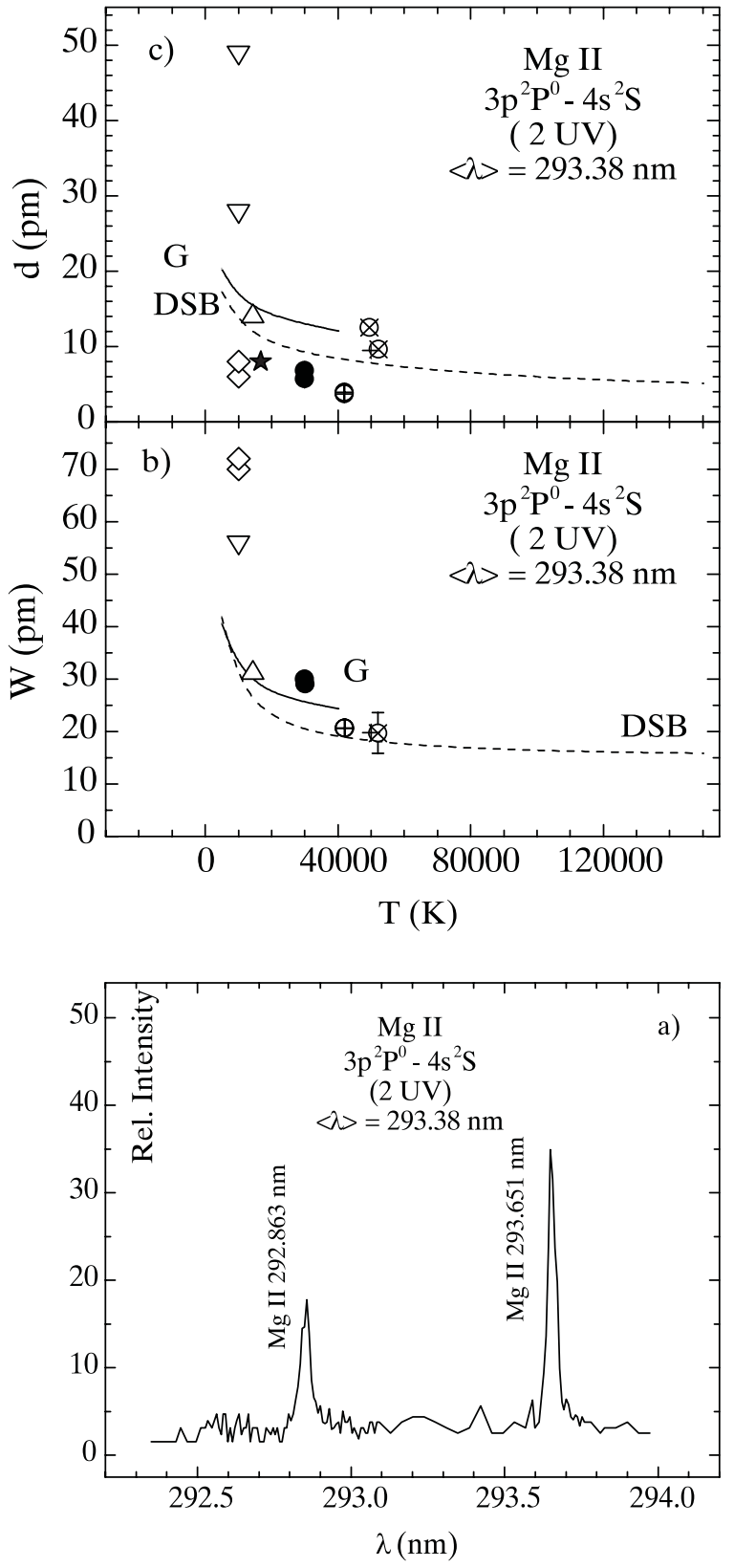

Fig. 3. $\mathrm{Mg}$ II line profiles in oxygen plasma a), Stark FWHM ( $W$ in pm) b) and shift $\left(d\right.$ in pm) c) values at $10^{23} \mathrm{~m}^{-3}$ electron density. Symbols $(\otimes),(\oplus)$ and $(\bullet)$ denote our results in helium, oxygen and argon-helium plasmas, respectively. Other experimental values are: $\triangle$, Fleurier et al. (1977); $\nabla$, Kusch \& Schweicker (1976); Purić \& Konjević (1972); $\diamond$, Helbig \& Kusch (1972). G and DSB denote theoretical electron widths and shifts calculated by Griem (1974) and Dimitrijević \& Sahal-Bréchot (1995), respectively. The symbol + denotes sum of the electron and helium ion contributions to the total Stark width and shift taken from Dimitrijević \& Sahal-Bréchot (1995). $\langle\lambda\rangle$ is the mean wavelength in the multiplet. Error bar represents estimated uncertainties.

symbol plus in Figs. 3b,c and 4a,b). In the case of the multiplet $1 \mathrm{UV}$ we have found very low negative Stark shift values. Within our experimental accuracy these are practically equal to zero in a wide range of the electron temperatures confirming

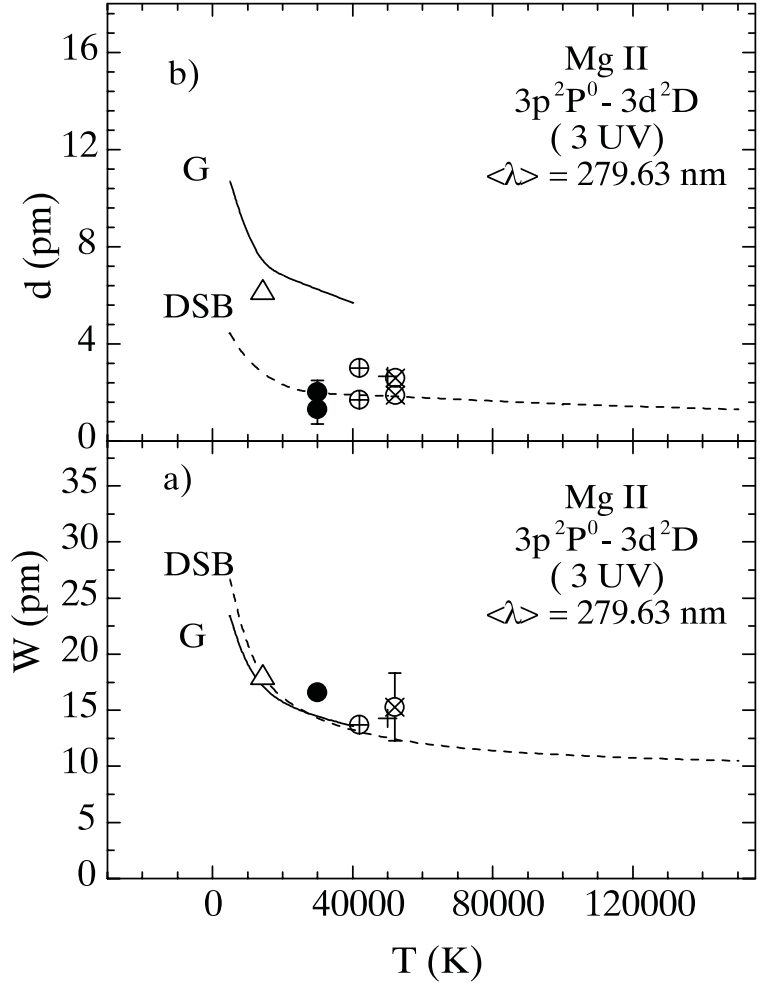

Fig. 4. Stark FWHM ( $W$ in pm) a) and shift $(d$ in pm) b) values at $10^{23} \mathrm{~m}^{-3}$ electron density for $\mathrm{Mg}$ II lines in the $3 \mathrm{UV}$ multiplet. The symbols are the same as in Fig. 3.

Table 1. Measured Mg II Stark FWHM $\left(W_{\mathrm{m}}\right)$ and shift $\left(d_{\mathrm{m}}\right)$ values at various electron temperatures $(T)$ and $1.0 \times 10^{23} \mathrm{~m}^{-3}$ electron density in various plasmas with corresponding accuracies. The letters a, $\mathrm{b}$ and $\mathrm{c}$ denote helium, oxygen and argon-helium plasmas, respectively. Asterix denotes $W_{\mathrm{m}}$ and $d_{\mathrm{m}}$ values in the helium plasma which agree very good with calculated ones using the SCPF approximation (Dimitrijević \& Sahal-Bréchot 1995) that include the electron and helium ion contribution in the Mg II line broadening and shift. Atomic data are taken from NIST (2004). Negative shift is toward the blue.

\begin{tabular}{c|c|c|c|r|r}
\hline \hline Transition & $\begin{array}{c}\lambda \\
(\mathrm{nm})\end{array}$ & Exp. & $\begin{array}{c}T \\
\left(10^{3} \mathrm{~K}\right)\end{array}$ & \multicolumn{1}{c|}{$\begin{array}{c}d_{\mathrm{m}} \\
(\mathrm{pm})\end{array}$} & \multicolumn{1}{c}{$\begin{array}{c}W_{\mathrm{m}} \\
(\mathrm{pm})\end{array}$} \\
\hline $3 \mathrm{~s}^{2} \mathrm{~S}-3 \mathrm{p}^{2} \mathrm{P}^{0}$ & 279.5528 & $\mathrm{a}$ & 52.3 & $-1.5 \pm 0.8$ & \\
$1 \mathrm{UV}$ & & $\mathrm{b}$ & 42.0 & $-0.5 \pm 0.8$ & \\
& \multirow{2}{*}{280.2705} & $\mathrm{c}$ & 30.0 & $-1.0 \pm 0.8$ & \\
& & $\mathrm{a}$ & 52.3 & $-0.5^{*} \pm 0.8$ & \\
& & $\mathrm{~b}$ & 42.0 & $0.4 \pm 0.8$ & \\
& $\mathrm{c}$ & 30.0 & $-0.2 \pm 0.8$ & \\
\hline $3 \mathrm{p}^{2} \mathrm{P}^{0}-4 \mathrm{~s}^{2} \mathrm{~S}$ & 292.8633 & $\mathrm{a}$ & 52.3 & $9.6^{*} \pm 0.8$ & $19.7^{*} \pm 12 \%$ \\
$2 \mathrm{UV}$ & & $\mathrm{b}$ & 42.0 & $3.9 \pm 0.8$ & $20.6 \pm 12 \%$ \\
& & $\mathrm{c}$ & 30.0 & $5.7 \pm 0.8$ & $29.0 \pm 12 \%$ \\
& \multirow{2}{*}{293.6510} & $\mathrm{a}$ & 49.4 & $12.5 \pm 0.8$ & $19.7^{*} \pm 12 \%$ \\
& & $\mathrm{~b}$ & 42.0 & $3.7 \pm 0.8$ & $20.6 \pm 12 \%$ \\
& & $\mathrm{c}$ & 30.0 & $6.8 \pm 0.8$ & $30.0 \pm 12 \%$ \\
\hline $\mathrm{p}^{2} \mathrm{P}^{0}-3 \mathrm{~d}^{2} \mathrm{D}$ & 279.0777 & $\mathrm{a}$ & 52.3 & $2.6^{*} \pm 0.8$ & $15.3^{*} \pm 12 \%$ \\
$3 \mathrm{UV}$ & & $\mathrm{b}$ & 42.0 & $3.0 \pm 0.8$ & $13.7 \pm 12 \%$ \\
& & $\mathrm{c}$ & 30.0 & $2.0 \pm 0.8$ & $16.6 \pm 12 \%$ \\
& 279.7998 & $\mathrm{a}$ & 52.3 & $1.9 \pm 0.8$ & $15.3^{*} \pm 12 \%$ \\
& & $\mathrm{~b}$ & 42.0 & $1.7 \pm 0.8$ & $13.7 \pm 12 \%$ \\
& & $\mathrm{c}$ & 30.0 & $1.3 \pm 0.8$ & $16.6 \pm 12 \%$ \\
\hline
\end{tabular}




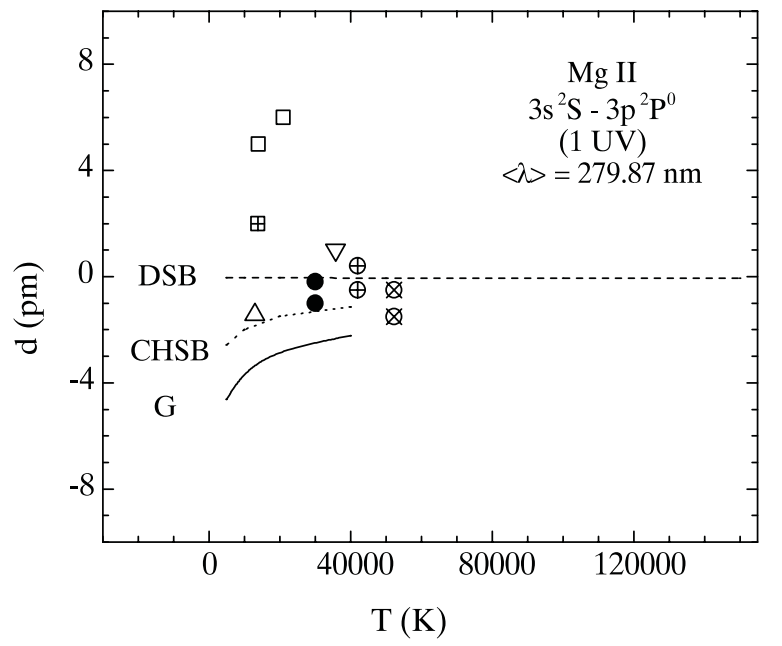

Fig. 5. Stark shift ( $d$ in pm) values at $10^{23} \mathrm{~m}^{-3}$ electron density for the resonance $\mathrm{Mg}$ II $h \& k$ lines. Symbols $(\otimes),(\oplus)$ and $(\bullet)$ denote our results in helium, oxygen and argon-helium plasmas, respectively. Other experimental values are: $\boxplus$ Chapelle \& Sahal-Bréchot (1970); $\square$, Roberts \& Barnard (1972); $\nabla$, Hadžiomerspahić et al. (1973); $\Delta$, Fleurier et al. (1977). G, CHSB and DSB denote theoretical electron shift values taken from Griem (1974), Chapelle \& Sahal-Bréchot (1970) and Dimitrijević \& Sahal-Bréchot (1995), respectively. $\langle\lambda\rangle$ is the mean wavelength in the multiplet.

the DSB Stark shift values calculated by SCPF (Dimitrijević \& Sahal-Bréchot 1995).

\section{Conclusion}

On the basis of the agreement between experimental and calculated $W$ and $d$ values we have found that the $279.0777 \mathrm{~nm}$, $279.7998 \mathrm{~nm}, 292.8633 \mathrm{~nm}$ and $293.6510 \mathrm{~nm} \mathrm{Mg}$ II lines have convenient Stark parameters useful for plasma modelling and diagnostic purposes.

Acknowledgements. This work is a part of the project "Determination of the atomic parameters on the basis of the spectral line profiles" (OI 1228) supported by the Ministry of Science, Technologies and Development of the Republic of Serbia.

\section{References}

Arav, N., Brotherton, M. S., Becker, R. H., et al. 2001, ApJ, 546, 140 Ashby, D. E. T. F., Jephcott, D. F., Malein, A., \& Raynor, F. A. 1965 , Appl. Phys., 36, 29
Bohm-Vitense, E., Mena-Werth, J., Carpenter, K. G., \& Robinson, R. D. 2001, ApJ, 550, 457

Chapelle, J., \& Sahal-Bréchot, S. 1970, A\&A, 6, 415

Charlton, J. C., Mellon, R. R., Rigby, J. R., \& Churchill, C. W. 2000, ApJ, 545, 635

Danezis, E., Nikolaidis, D., Lyratzi, V., et al. 2003, ApJS, 284, 1119

Davies, J. I., \& Vaughan, J. M. 1963, ApJ, 137, 1302

Dimitrijević, M. S., \& Sahal-Bréchot, S. 1995, Bull. Astron. Belgrade, 151,101

Djeniže, S., Srećković, A., Platiša, M., et al. 1990a, JQSRT, 44, 405

Djeniže, S., Srećković, A., \& Labat, J. 1990b, Z. Phys. D, 17, 85

Djeniže, S., Srećković, A., Labat, J., Konjević, R., \& Popović, L. 1991, Phys. Rev. A, 44, 410

Djeniže, S., Srećković, A., Labat, J., Konjević, R., \& Brnović, M. 1992, Z. Phys. D, 24, 1

Djeniže, S., \& Bukvić, S. 2001, A\&A, 365, 252

Djeniže, S., Srećković, A., Jelisavčić, M., \& Bukvić, S. 2002, A\&A, 389, 1086

Djeniže, S., Bukvić, S., Srećković, A., \& Kalezić, S. 2003, A\&A, 406, 759

Eracleous, M., \& Halpern, J. P. 2003, ApJ, 599, 886

Fleurier, C., Sahal-Bréchot, S., \& Chapelle, J. 1977, JQSRT, 17, 595

Griem, H. R. 1964, Plasma Spectroscopy (New York: MC Graw Hill Inc.)

Griem, H. R. 1974, Spectral Line Broadening by Plasmas (New York: Academic Press)

Hadžiomerspahić, D., Platiša, M., Konjević, N., \& Popović, M. 1973, Z. Phys., 262, 169

Helbig, V., \& Kusch, H. J. 1972, A\&A, 20, 299

Konjević, N., Lesage, A., Fuhr, J. R., \& Wiese, W. L. 2002, J. Phys. Chem. Ref. Data, 31, 819

Kusch, H. J., \& Schweicker, H. 1976, A\&A, 53, 59

Lesage, A. 1995, in Astrophysical applications of powerful new databases, ed. S. J. Adelman, \& W. L. Wiese (San Francisco: ASP), vol. 78

Lobel, A., \& Dupree, A. K. 2000, ApJ, 545, 454

Luttermoser, D. G. 2000, ApJ, 536, 923

NIST 2004, Atomic spectra database lines data (Wavelengths ordered) http://www. physics.nist.org

Popović, L. C., Stanić, N., Kubičela, A., \& Bon, E. 2001, A\&A, 367, 780

Purić, J., \& Konjević, N. 1972, Z. Phys., 249, 440

Roberts, D. E., \& Barnard, A. J. 1972, JQSRT, 12, 1205

Sahal-Bréchot, S. 1969a, A\&A, 1, 91

Sahal-Bréchot, S. 1969b, A\&A, 2, 322

Uitenbroek, H., \& Briand, C. 1995, ApJ, 447, 453

Wood, B. E., \& Karovska, M. 2000, ApJ, 543, 922

Zeippen, C. J. 1995, Phys. Scr., T58, 43 